\title{
Vitamin D and kidney disease
}

\author{
Lisa Keung, Farzana Perwad* \\ University of California San Francisco, San Francisco, CA, United States
}

\section{A R T I C L E I N F O}

\section{Keywords:}

Calcium

Vitamin D

Parathyroid hormone (PTH)

Parathyroid hormone related protein (PTHrP) Kidney

\begin{abstract}
A B S T R A C T
Calcium and phosphorus are essential minerals required for many critical biologic functions including cell signaling, energy metabolism, skeletal growth and integrity. Calcium and phosphate homeostasis are maintained primarily by regulation of epithelial calcium and phosphate cotransport in the kidney and intestine, processes that are tightly regulated by hormones including 1,25 dihydroxyvitamin $\mathrm{D}\left(1,25(\mathrm{OH})_{2} \mathrm{D}\right)$, fibroblast growth factor 23 (FGF23) and parathyroid hormone (PTH). In patients with chronic kidney disease (CKD), as renal function declines, disruption of feedback loops between these hormones have adverse consequences on several organ systems, including the skeleton, heart and vascular system. CKD-associated mineral and bone disorder (CKD-MBD) is defined as a systemic disorder of mineral and bone metabolism due to CKD manifested by abnormalities of calcium, phosphorus, PTH or vitamin D metabolism, abnormalities of bone turnover, mineralization and volume, and ectopic soft tissue calcification. Complications of CKD-MBD include vascular calcification, stroke, skeletal fracture and increased risk of death. Increased FGF23 and PTH concentrations, and $1,25(\mathrm{OH})_{2} \mathrm{D}$ deficiency contribute to the pathogenesis of CKD-MBD. Therefore, treatment of patients with CKDMBD is focused on restoring the feedback loops to maintain normal calcium and phosphate balance to prevent skeletal and cardiovascular complications.
\end{abstract}

\section{Case report}

\subsection{Clinical presentation}

This is a case report of a two and half-year old male with end stage renal disease (ESRD) secondary to obstructive uropathy on peritoneal dialysis who developed acute onset of hypercalcemia while on therapy with calcitriol and ergocalciferol for management of mineral and bone disorder related to chronic kidney disease (CKD-MBD). Patient was hospitalized for severe anemia and was noted to have acute onset of hypercalcemia (peak serum calcium- $15 \mathrm{mg} / \mathrm{dl}$, ionized calcium $2.28 \mathrm{mmol} / \mathrm{L}$ ) during the hospital admission. A low hemoglobin $(6.1 \mathrm{mg} / \mathrm{dl})$ was detected on routine laboratory testing in the outpatient clinic and he was admitted for a blood transfusion. He was otherwise asymptomatic.

\subsection{Past medical history}

Patient was diagnosed with posterior urethral valves at birth and developed significant deterioration of kidney function for which he was initiated on continuous cycling peritoneal dialysis (CCPD) therapy at five months of age. His other medical conditions related to ESRD include anemia, growth failure and malnutrition, hypertension and secondary hyperparathyroidism. Patient was on standard of care therapy with calcitriol to treat secondary hyperparathyroidism and ergocalciferol to treat vitamin D deficiency. Prior to admission, patient had normal PTH and calcium levels (Table 1). In the outpatient clinic, calcitriol was started when PTH levels rose to $1458 \mathrm{ng} / \mathrm{L}$ and the dose titrated to maintain PTH levels between 150 and $300 \mathrm{ng} / \mathrm{L}$. Due to longstanding biochemical abnormalities related to CKD-MBD, he developed severe bone deformities noted on X-Rays of the skeleton (Figs. 1 and 2): there was sclerosis in the proximal metadiaphysis of the proximal humerus bilaterally, proximal and distal metadiaphyses of the femurs bilaterally, sclerosis and bowing deformity of the radius, ulna, tibia and fibula bilaterally and metaphyseal cupping and fraying of the bilateral radii and ulnas consistent with rickets. These skeletal changes are classic for poorly controlled secondary hyperparathyroidism and CKD-MBD.

\subsection{Clinical findings}

Patient was asymptomatic with no h/o lethargy, constipation, weight loss or polydipsia. Differential diagnosis for hypercalcemia included vitamin D intoxication, incorrect dosing or accidental overdose

\footnotetext{
* Corresponding author.

E-mail address: farzana.perwad@ucsf.edu (F. Perwad).
} 
Table 1

Laboratory data at clinical diagnosis.

\begin{tabular}{llll}
\hline Biochemistries & $\begin{array}{l}1 \text { month prior } \\
\text { to admission }\end{array}$ & $\begin{array}{l}\text { At clinical } \\
\text { presentation }\end{array}$ & Reference range \\
\hline Calcium & 10.8 & 15 & $8.8-10.3 \mathrm{mg} / \mathrm{dL}$ \\
Ionized calcium & - & 2.28 & $1.16-1.36 \mathrm{mmol} / \mathrm{L}$ \\
Phosphorus & - & 6.5 & $3.1-6.0 \mathrm{mg} / \mathrm{dL}$ \\
Albumin & 3.8 & 2.7 & $3.1-4.8 \mathrm{~g} / \mathrm{L}$ \\
Bone specific alkaline & - & 105 & $40-120 \mathrm{U} / \mathrm{L}$ \\
$\quad$ phosphatase & & & \\
PTH & 174 & 19 & $12-65 \mathrm{ng} / \mathrm{L}$ \\
$25 \mathrm{OHD}$ & 19 & 34 & $20-50 \mathrm{ng} / \mathrm{ml}$ \\
1,25(OH) ${ }_{2} \mathrm{D}$ & - & 11 & $31-87 \mathrm{pg} / \mathrm{ml}$ \\
PTHrP & - & 16 & $<2 \mathrm{pmol} / \mathrm{L}$ \\
Vitamin A & - & 330 & $20-43 \mu \mathrm{dg} / \mathrm{dl}$ \\
\hline
\end{tabular}

of calcitriol. A full diagnostic workup was initiated (Table 1). Anemia was attributed to inadequate erythropoietin therapy and the dose was adjusted during hospitalization. Hemoglobin improved with blood transfusion.

Home medication list: calcitriol $0.5 \mu \mathrm{g}$ per gastrointestinal tube (GTube) twice a day, erythropoietin 1800 Units subcutaneously three times a week, ergocalciferol $3600 \mathrm{IU}$ per G-Tube daily, ferrous sulfate $15 \mathrm{mg}$ of elemental iron Per G Tube two times daily, folic acid-b complex-vitamin c (NEPHRONEX) $900 \mu \mathrm{g} / 5 \mathrm{~mL}, 1 \mathrm{ml}$ per G-Tube daily, sevelamer carbonate $0.4 \mathrm{~g}$ per G-Tube three times daily with meals, sodium chloride $9 \mathrm{mEq}$ by Per G Tube two times daily, somatropin $0.6 \mathrm{mg}$ subcutaneously six times a week.

\subsection{Diagnostic workup challenges and timeline}

One month prior to admission, patient had normal PTH and serum calcium levels (Table 1 ). Shortly after admission, serum calcium increased from $9.6 \mathrm{mg} / \mathrm{dl}$ on day 1 to $15 \mathrm{mg} / \mathrm{dl}$ on day 5 , and ionized calcium peaked at $2.28 \mathrm{mmol} / \mathrm{L}$ on day 5 on the same home dose of calcitriol. Given that there was no change in the medications, it was suspected that calcitriol was being administered infrequently at home or incorrectly via G-tube. With regular administration of calcitriol by nursing staff, it was thought that the patient was now responsive to calcitriol with increased intestinal absorption of calcium and subsequent hypercalcemia. Therefore, the working diagnosis for hypercalcemia was calcitriol overdose or vitamin D toxicity. Serum PTH, $25 \mathrm{OHD}$ and $1,25(\mathrm{OH})_{2} \mathrm{D}$ levels were drawn and both ergocalciferol and calcitriol therapy were discontinued. Given calcitriol half life is short $(\sim 27 \mathrm{~h}$ in children) it was expected that serum calcium levels will normalize within a few days. However, $25 \mathrm{OHD}$ and $1,25(\mathrm{OH})_{2} \mathrm{D}$ levels were within normal range ruling out calcitriol overdose and vitamin D toxicity. Serum calcium levels remained elevated during hospital stay. PTH levels were appropriately suppressed at $19 \mathrm{ng} / \mathrm{L}$ ruling out parathyroid hormone related disorders and a more extensive workup for hypercalcemia was initiated. Urine calcium excretion was not measured because patient had ESRD with oliguria. Differential diagnosis at this time point included hyperthyroidism, adrenal insufficiency, hypercalcemia of malignancy, granulomatous diseases and vitamin A toxicity. Sarcoidosis is very rare in this age group and was not considered in the differential diagnosis. PPD test for tuberculosis was negative. Thyroid hormone and cortisol levels were within normal limits. Patient had significantly elevated $\mathrm{N}$ terminal PTHrP (16 pmol/L, normal $<2.0 \mathrm{pmol} / \mathrm{L})$ and vitamin A levels $(330 \mu \mathrm{g} / \mathrm{dl}$, normal $20-43 \mu \mathrm{g} / \mathrm{dL}$ ) (Table 1). Patient's hospital stay was extended to investigate a malignancy that would cause an increased PTHrP production. MRI and CT scans of head, neck, chest and abdomen were negative for a malignant process. He had no evidence of a hematologic malignancy with a negative workup for lymphoma and leukemia.

\subsection{Therapeutic intervention}

a. Pharmacologic intervention- Ergocalciferol and calcitriol were discontinued, patient received peritoneal dialysis with low calcium dialysate solution throughout admission. Serum calcium, PTH and PTHrP levels were monitored at regular intervals.

b. Nutritional intervention-Patient's nutritional regimen was closely monitored by a renal dietician. With the onset of hypercalcemia, the volume of formula was decreased by $50 \%$ to decrease intestinal calcium load. For age, patient's daily calcium requirement was $700 \mathrm{mg}$ per day. His original nutrition prescription provided $680 \mathrm{mg}$ calcium per day before interventions were initiated to treat hypercalcemia. Vitamin A level was significantly high $(330 \mu \mathrm{g} / \mathrm{dL})$ but detailed review of his dietary intake showed his intake was $90 \%$ dietary reference intake (DRI) for vitamin A for his age and he did not receive any additional supplementation. Serum calcium levels decreased slightly with this nutritional intervention. However, due to concerns of inadequate macronutrient intake, his feeds were adjusted to provide an intake with normal calories and protein but with reduced calcium $(140 \mathrm{kcal} / \mathrm{kg}, 2.1 \mathrm{~g}$ protein $/ \mathrm{kg}, 295 \mathrm{mg}$ calcium, $813 \mathrm{IU}$ vitamin A and $21 \mathrm{IU}$ vitamin D per day). His daily calcium intake ranged from 159 to $250 \mathrm{mg}$ per day. Despite $\sim 60 \%$ reduction in calcium intake, serum calcium level was $12.7 \mathrm{mg} / \mathrm{dl}$ at the time of hospital discharge. In the outpatient clinic, serum calcium remained elevated $(10.6-13.0 \mathrm{mg} / \mathrm{dl})$ for considerable length of time despite these measures. He received a deceased donor kidney transplant 5 months after presentation and serum calcium and PTHrP levels returned to normal values (Table 2).

\subsection{Strengths and limitations of our approach to this case}

In this case report of a toddler with ESRD on peritoneal dialysis we highlight the complex pathophysiology of secondary hyperparathyroidism due to renal disease and the difficulties in maintaining normal calcium and phosphorus levels to promote optimal skeletal health. Children must maintain a positive calcium and phosphorus balance to meet the demands of a growing skeleton. However, treatment of secondary hyperparathyroidism must be undertaken cautiously to prevent hypercalcemia and its complications. Hypocalcemia is a common clinical presentation in patients with ESRD due to $1,25(\mathrm{OH})_{2} \mathrm{D}$ deficiency resulting in decreased intestinal calcium absorption and subsequent hypocalcemia. Hypercalcemia in patients with CKD on the other hand is an adverse effect of treatment of secondary hyperparathyroidism as illustrated in this case report. Other differential diagnosis for hypercalcemia in infants and children include parathyroid related disorders (multiple endocrine neoplasia (MEN) syndrome I and II, Jansen's metaphyseal chondrodyplasia), familial hypocalciuric hypercalciuria, Vitamin A and D intoxication, William's Syndrome, calcium sensing receptor disorders, granulomatous diseases and malignancy. We systematically ruled out inherited disorders, malignancy and granulomatous diseases in our patient. Two positive findings from our investigations were elevated vitamin A and PTHrP levels. Of note, caution is warranted in interpreting PTHrP levels in CKD as the carboxy terminal assay values are increased in patients with CKD. $\mathrm{N}$ terminal PTHrP assays must be performed to confirm the findings as we did in our patient.

\subsection{Discussion of the relevant medical literature}

In rare instances, hypercalcemia has been reported in infants with Congenital Anomalies of the Kidney and Urinary Tract (CAKUT). In a series of 99 patients with CAKUT, 15 patients were noted to have hypercalcemia in the absence of vitamin $\mathrm{D}$ or calcitriol treatment (Al et al., 2011). Mean duration of hypercalcemia was $5.2 \pm 6.0$ months and mean corrected calcium was $12.3 \mathrm{mg} / \mathrm{dl}$. Only 10 patients had PTH and 25OH D levels measured but PTHrP levels were not measured in 

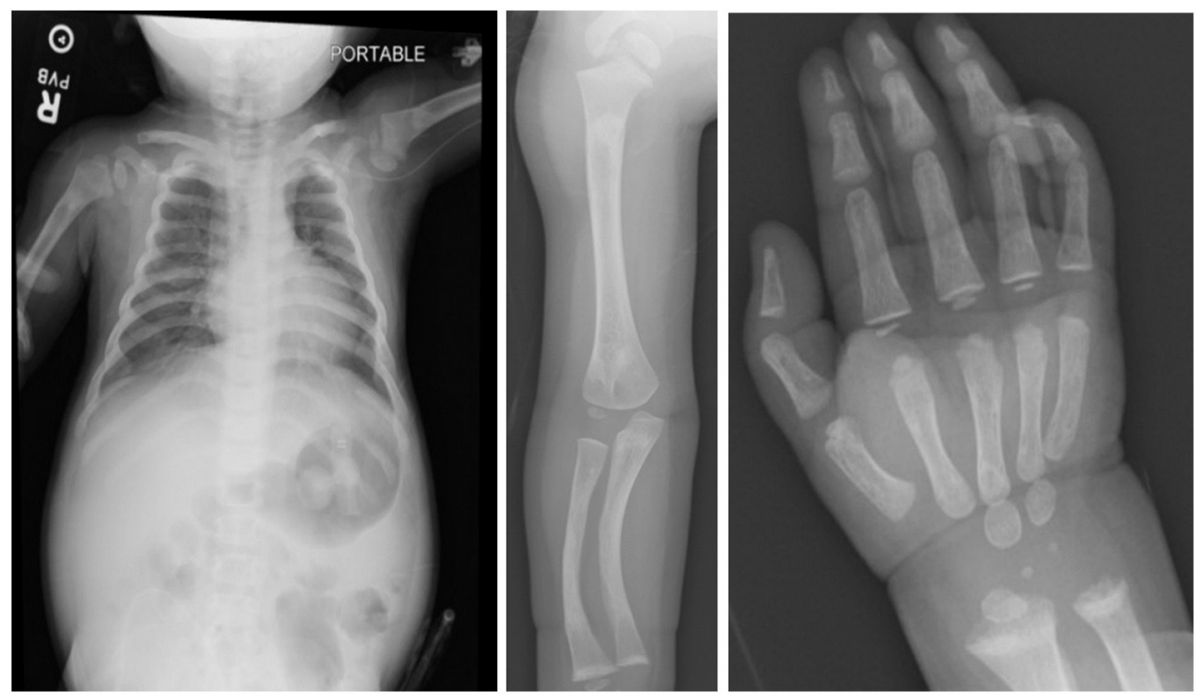

Fig. 1. Skeletal X-Ray of chest, abdomen and upper extremities. There is sclerosis in the proximal metadiaphysis of the proximal humerus bilaterally. There is sclerosis and bowing deformity and metaphyseal cupping and slight fraying of the radius and ulna.
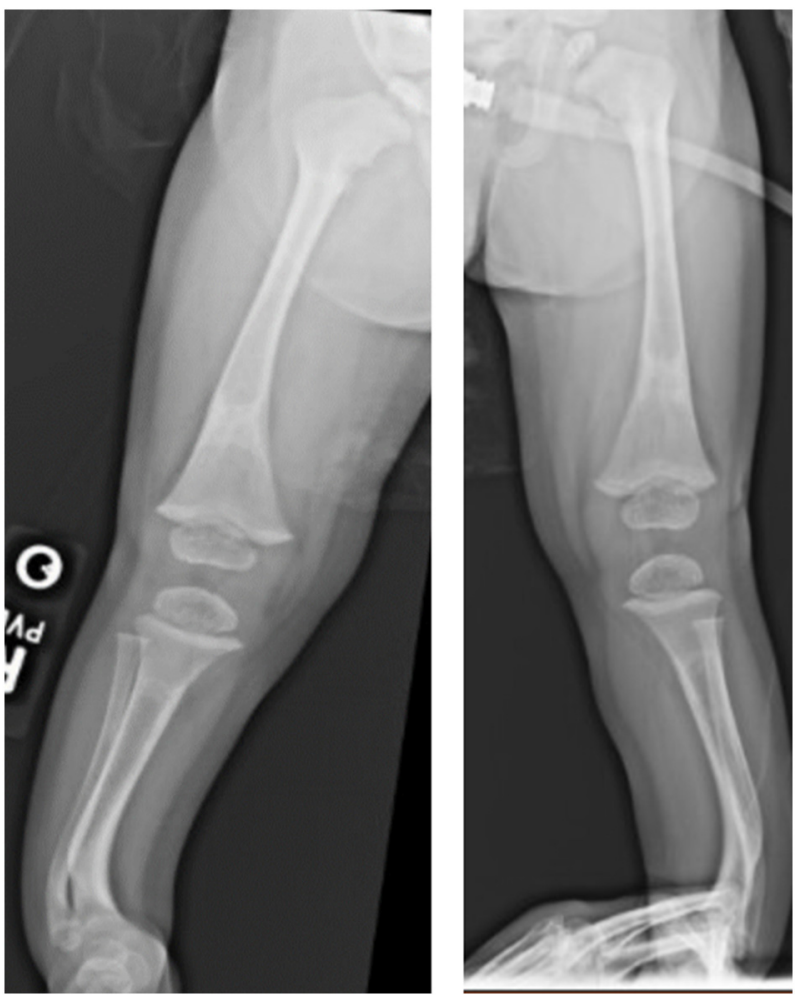

Fig. 2. Skeletal X-Ray of lower extremities. There is sclerosis in the proximal and distal metadiaphyses of the bilateral femurs. There is sclerosis and bowing of the tibias and fibulas bilaterally. this series. Elevated PTH levels were observed in 3/10 patients and increased 25OHD levels was observed in only 1 patient. To date, there are two case reports of hypercalcemia associated with increased PTHrP levels in children with CAKUT who are not on dialysis (Grob et al., 2013; Kodous et al., 2015). Mechanisms by which PTHrP production is increased in CKD associated with CAKUT are unknown. In both case reports, malignancy was ruled out by imaging studies. Treatment of hypercalcemia in the above mentioned studies included hydration, furosemide, bisphosphonate therapy and reduced calcium intake. In our patient, we reduced dietary calcium intake with some clinical improvement but did not try other measures as our patient was on dialysis therapy.

\subsection{Conclusions}

This case illustrates the significant challenges faced in clinical practice in the management of CKD-MBD in children. This patient had severe CKD-MBD evidenced by multiple skeletal deformities and growth retardation. Treatment with calcitriol was initiated when PTH levels were significantly elevated $(1458 \mathrm{ng} / \mathrm{L})$ and patient had increased risk of high bone turnover disease from uncontrolled hyperparathyroidism. However, maintaining optimal PTH, calcium and phosphorus levels in a child with CKD while avoiding complications such as hypercalcemia proved to be difficult in this patient. Despite dietary interventions and discontinuation of calcitriol and ergocalciferol, patient had persistent hypercalcemia and overly suppressed PTH levels which increased the risk of low bone turn over disease. Our case was unique in that hypercalcemia developed acutely while the patient was hospitalized and persisted for several months till the time of kidney transplantation despite measures to treat hypercalcemia. Although calcitriol and vitamin $D$ therapy may have aggravated hypercalcemia at the onset of clinical diagnosis, high PTHrP and vitamin A levels contributed to the persistently high calcium levels that corrected only after kidney transplantation. Management of CKD-MBD is particularly

Table 2

Laboratory data during clinical course.

\begin{tabular}{|c|c|c|c|c|c|}
\hline Biochemistries & At hospital discharge & 1 month after discharge & 2 months after discharge & Post kidney transplant & Reference range \\
\hline Calcium & 12.7 & 12.1 & 11.0 & 8.9 & $8.8-10.3 \mathrm{mg} / \mathrm{dL}$ \\
\hline Ionized calcium & 1.51 & 1.45 & 1.37 & 1.16 & $1.16-1.36 \mathrm{mmol} / \mathrm{L}$ \\
\hline PTH & 174 & 87 & 109 & 129 & $12-65 \mathrm{ng} / \mathrm{L}$ \\
\hline PTHrP & - & - & 7.9 & 1.4 & $<2 \mathrm{pmol} / \mathrm{L}$ \\
\hline
\end{tabular}


challenging in a child with increased demand for calcium and phosphorus to meet the needs of a growing dynamic skeleton on one hand but simultaneously avoiding overcompensation (i.e. oversuppressed PTH), hypercalcemia and ectopic calcifications of the cardiovascular system.

\section{Introduction}

Calcium is the most abundant electrolyte in the human body, and in healthy adults, accounts for about $2 \%$, or $1300 \mathrm{~g}$, of body weight. From birth to approximately 20 years of age, when the skeleton reaches its full size and density, calcium content increases by some 40 -fold (Widdowson and Dickerson, 1964). During this period, the increase in skeletal weight and calcium content requires the net retention of about 150 to $200 \mathrm{mg}$ of calcium per day. Phosphorus accounts for about $0.6 \%$ of body weight at birth and about $1 \%$ of body weight, or 600 to $700 \mathrm{~g}$, in the adult ( $\mathrm{Al}$ et al., 2011). Thus, in growing individuals, calcium and phosphorus balance must be positive to meet the needs of skeletal growth and consolidation. In adults, calcium and phosphorus balance is zero after peak bone mass is attained and becomes slightly negative as bone is slowly lost with aging. Calcium and phosphorus deficiency results in rickets in children and osteomalacia in both children and adults.

Vitamin D homeostasis is critical for control of calcium and phosphate balance in health and disease states. Circulating levels of the active form of vitamin $\mathrm{D}, 1,25$ dihydroxyvitamin $\mathrm{D}\left(1,25(\mathrm{OH})_{2} \mathrm{D}\right)$ is largely determined by $1,25(\mathrm{OH})_{2} \mathrm{D}$ production in the kidney. In chronic kidney disease (CKD), vitamin D metabolism is perturbed contributing to CKD-associated mineral and bone disorder (CKD-MBD). The pathophysiology of CKD-MBD is complex and it involves the interactions between the hormones that regulate skeletal biology and calcium and phosphorus homeostasis. Parathyroid hormone (PTH), 1,25( $(\mathrm{OH})_{2} \mathrm{D}$ and fibroblast growth factor 23 (FGF23) are the principal regulators of bone and mineral homeostasis in CKD; as renal function declines, disruption of feedback loops between these hormones have adverse consequences on several organ systems, including the skeleton, heart and vascular system (Sabbagh et al., 2012; Wesseling-Perry et al., 2012; Pereira et al., 2009; Fang et al., 2014; Di Marco et al., 2014; Faul et al., 2011). Hence, treatment of patients with CKD-MBD is focused on restoring the feedback loops between PTH, 1,25(OH $)_{2} \mathrm{D}$ and FGF23 to maintain normal calcium and phosphate homeostasis. This review will focus on the role of vitamin $\mathrm{D}$ in the pathophysiology and management of CKDMBD.

\subsection{Pathophysiology}

\subsubsection{Vitamin D metabolism in health and kidney disease}

As one of the principal hormonal regulators of calcium and phosphorus metabolism, $1,25(\mathrm{OH})_{2} \mathrm{D}$ is critically important for normal growth and mineralization of bone. The classical actions of $1,25(\mathrm{OH})_{2} \mathrm{D}$ are to stimulate calcium and phosphorus absorption from the intestine, thereby maintaining plasma concentrations at sufficient levels for normal growth and mineralization of bone. $1,25(\mathrm{OH})_{2} \mathrm{D}$ also has direct actions on bone, kidney, skin, parathyroid gland, and many other tissues unrelated to mineral metabolism (Feldman et al., 1996).

Vitamin $\mathrm{D}$ exists as either ergocalciferol (vitamin $\mathrm{D}_{2}$ ) produced by plants, or cholecalciferol (vitamin $\mathrm{D}_{3}$ ) produced by animal tissues and by the action of near ultraviolet radiation on 7-dehydrocholesterol in human skin. Both forms of vitamin D are biologically inactive prohormones that must undergo successive hydroxylations at carbons \#25 and \#1 before they can bind to and activate the vitamin $D$ receptor. The 25-hydroxylation of vitamin D occurs in the liver, catalyzed by one or more enzymes including the mitochondrial enzyme CYP27A1 and the microsomal enzyme CYP2R1 (Cali and Russell, 1991; Cheng et al., 2004). The activity of hepatic 25-hydroxylation is not under tight physiologic regulation, and thus circulating concentrations of 25OHD are determined primarily by dietary intake of vitamin D and exposure to sunlight. Although 25OHD is the most abundant form of vitamin D in the blood, it has minimal capacity to bind to the vitamin D receptor and elicit a biologic response.

The active form of vitamin $\mathrm{D}, 1,25(\mathrm{OH})_{2} \mathrm{D}$, is produced by the $1 \alpha$ hydroxylation of $25 \mathrm{OHD}$ by the mitochondrial enzyme, 25-hydroxyvitamin D-1 $\alpha$-hydroxylase (1 $\alpha$-hydroxylase) (Fu et al., 1997a; Fu et al., 1997b). The circulating concentration of $1,25(\mathrm{OH})_{2} \mathrm{D}$ primarily reflects its synthesis in the proximal tubule of the kidney; however, $1 \alpha$ hydroxylase activity also is found in keratinocytes, macrophages, and osteoblasts (Bikle et al., 1986; Adams et al., 1983; Howard et al., 1981). $1 \alpha$-Hydroxylation is the rate-limiting step in the bioactivation of vitamin D, and enzyme activity in the kidney is tightly regulated by PTH, calcium, phosphorus, 1,25(OH) 2 D and FGF23 (Henry, 1979; Carpenter TO et al., 1992; Murayama et al., 1999; Portale et al., 2011). The other important vitamin D-metabolizing enzyme, the 25-hydroxyvitamin D24-hydroxylase (24-hydroxylase), is found in kidney, intestine, lymphocytes, fibroblasts, bone, skin, macrophages, and possibly other tissues (Tanaka and Deluca, 1984; Armbrecht et al., 1992). The enzyme can catalyze the 24-hydroxylation of $25 \mathrm{OHD}$ to $24,25(\mathrm{OH})_{2} \mathrm{D}$ and that of $1,25(\mathrm{OH})_{2} \mathrm{D}$ to $1,24,25(\mathrm{OH})_{3} \mathrm{D}$; both reactions initiate the metabolic inactivation of vitamin D via the C24-oxidation pathway. The kidney and intestine are major sites of hormonal inactivation of vitamin D by virtue of their abundant 24-hydroxylase activity.

FGF23 is a bone-derived circulating peptide that primarily acts on the kidney to regulate phosphate and vitamin D homeostasis. FGF23 inhibits renal tubular phosphate cotransport to induce phosphaturia and lower serum phosphorus concentrations. FGF23 suppresses the renal production and serum concentration of $1,25(\mathrm{OH})_{2} \mathrm{D}$ by suppressing $1 \alpha$-hydroxylase mRNA and protein expression and stimulating 24hydroxylase mRNA expression (Shimada et al., 2001; Bai et al., 2003; Larsson et al., 2004; Perwad et al., 2007). In CKD, several human and animal studies have established that the primary reason for early $1,25(\mathrm{OH})_{2} \mathrm{D}$ deficiency is likely an increase in FGF23 levels rather than the actual loss of nephron mass which occurs in later stages of CKD (Gutierrez et al., 2005; Portale et al., 2014; Isakova et al., 2011a; Hasegawa et al., 2010). 1,25(OH $)_{2}$ D deficiency contributes to the pathogenesis of CKD-MBD including secondary hyperparathyroidism and abnormalities in the skeletal and cardiovascular system. Therefore, correction of $1,25(\mathrm{OH})_{2} \mathrm{D}$ deficiency is a key component of prevention and treatment for CKD-MBD.

\subsection{2. $C K D-M B D$}

Kidney Disease: Improving Global Outcomes (KDIGO) is an international organization established in 2003 to improve the care and outcomes of kidney disease patients worldwide. The term CKD-MBD was established in 2006 by KDIGO and is defined as a systemic disorder of mineral and bone metabolism due to CKD manifested by either one or a combination of the following: a) Abnormalities of calcium, phosphorus, PTH or vitamin D metabolism, b) Abnormalities of bone turnover, mineralization, volume, linear growth or strength, and, c) Vascular or other soft tissue calcification (Moe et al., 2006). Of note, the traditional term "renal osteodystrophy" is now exclusively used to define abnormalities in bone morphology associated with CKD and can only be made by bone biopsy (KDIGO, 2009).

a) Abnormalities of calcium, phosphorus, PTH and vitamin D metabolism in CKD-MBD. Secondary hyperparathyroidism is a component of CKD-MBD, begins early in the course of $\mathrm{CKD}$, and its prevalence increases as kidney function deteriorates. As glomerular filtration rate (GFR) declines, the earliest clinically detectable abnormality in the course of CKD in children (Portale et al., 2014) and adults (Isakova et al., 2011a) is a rise in plasma FGF23 levels. However, the mechanisms by which FGF23 production in bone increases in early CKD are poorly understood (Shigematsu et al., 2004; David et al., 2016). Changes in FGF23 levels occur when GFR falls below $60 \mathrm{ml} / \mathrm{min} / 1.73 \mathrm{~m}^{2}$ and is followed by a decline in serum 


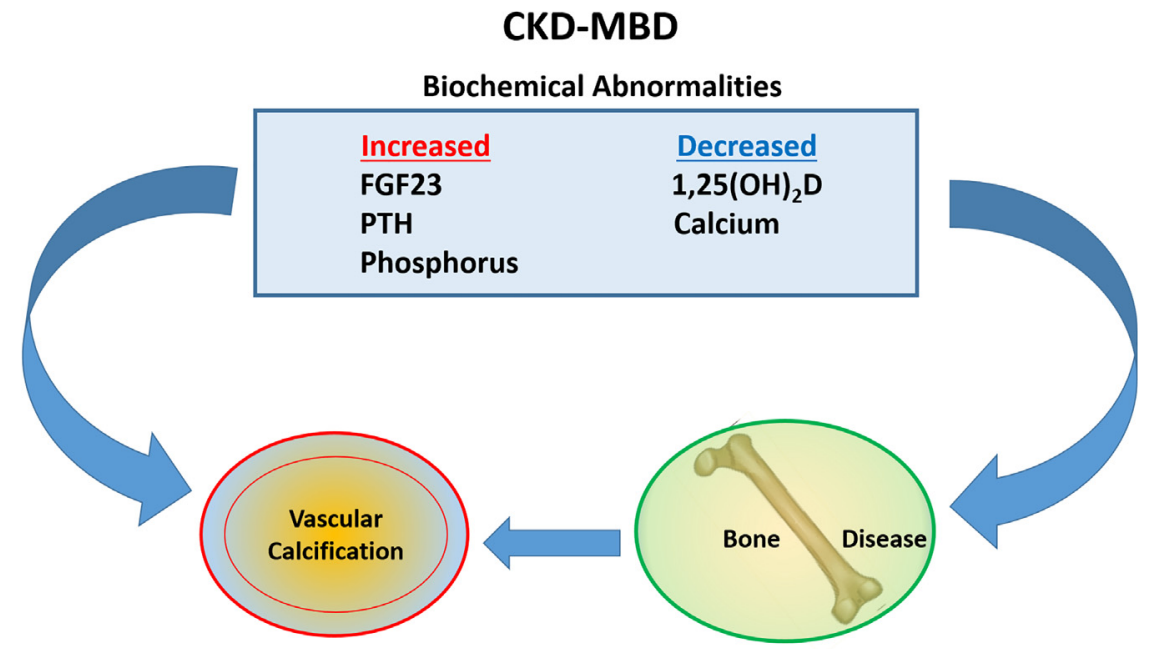

Fig. 3. Pathophysiology of CKD-MBD.

$1,25(\mathrm{OH})_{2} \mathrm{D}$ and subsequent rise in PTH levels when GFR falls below $50 \mathrm{ml} / \mathrm{min} / 1.73 \mathrm{~m}^{2}$. All of these changes occur long before increases in serum phosphorus levels and hypocalcemia are evident (Levin et al., 2007). Therefore, serum calcium and phosphorus levels are not reliable biomarkers for detection of early CKD-MBD. $1,25(\mathrm{OH})_{2} \mathrm{D}$ deficiency plays a major role in the development of secondary hyperparathyroidism by promoting parathyroid gland growth (hyperplasia) and increased PTH synthesis in part through loss of the ability to upregulate vitamin D receptor expression within parathyroid cells (Delmez et al., 1989; Sugimoto et al., 1988; Chan et al., 1986; Denda et al., 1996). Other factors that contribute to rise in PTH levels as renal function declines are hyperphosphatemia and hypocalcemia. With progressive loss of renal function, phosphate excretion is maintained by reducing the tubular reabsorption of filtered phosphate, an effect mediated by FGF23 and PTH. However, these beneficial adaptive increases in PTH and FGF23 to increase urinary phosphate excretion become maladaptive in the long term with adverse impact on the skeleton and cardiovascular system (Fig. 3).

b) Abnormalities of bone turnover, mineralization and volume: role of vitamin $\mathrm{D}$ in skeletal complications related to CKD. The gold standard for the diagnosis and classification of renal osteodystrophy is bone biopsy. Bone pathology is described in terms of high, normal, or low bone turnover (T), mineralization (M) or volume (V) to provide a comprehensive assessment of bone quality as per KDIGO recommendations (KDIGO, 2009). The traditional types of renal osteodystrophy have been defined on the basis of turnover and mineralization as follows: mild renal osteodystrophy- slight increase in turnover and normal mineralization; osteitis fibrosa- increased turnover and normal mineralization; osteomalacia- decreased turnover and abnormal mineralization; adynamic bone- decreased turnover and acellularity; mixed, increased turnover with abnormal mineralization (Table 3). However, in clinical practice bone biopsies are seldom performed and surrogate markers such as PTH, calcium and phosphorus are used to assess bone health and to guide therapy despite the fact that such markers are not sensitive or specific in diagnosing bone disease in CKD.

In adults and children, bone disease develops as early as CKD stage 2 (GFR 60 to $89 \mathrm{~mL} / \mathrm{min} / 1.73 \mathrm{~m}^{2}$ ) (Wesseling-Perry et al., 2012; Hamdy et al., 1995; Bacchetta et al., 2012; Coen et al., 2002; Mazzaferro et al., 1990; Coen et al., 1986; Coen et al., 1984). Bone biopsies in children with CKD 2-4 showed a lower serum calcium and higher PTH levels are associated with defective mineralization (Wesseling-Perry et al., 2012; Mathias et al., 1993; Goodman et al.,
1994). Although, $1,25(\mathrm{OH})_{2} \mathrm{D}$ and $25 \mathrm{OHD}$ levels have been associated with lower cortical bone mineral density in patients with CKD by peripheral quantitative computed tomography (pQCT), these parameters are not useful to determine subtypes of bone disease (Denburg et al., 2013). At the cellular level, $1,25(\mathrm{OH})_{2} \mathrm{D}$ plays a critical role in maintenance of skeletal health; $1,25(\mathrm{OH})_{2} \mathrm{D}$ regulates bone mineralization via control of calcium and phosphate homeostasis and regulation of PTH and FGF23 production. $1,25(\mathrm{OH})_{2} \mathrm{D}$ also has a direct effect on chondrocyte differentiation and function, bone mineralization, volume and turnover by virtue of its actions to regulate osteoblast and osteoclast activity (Bikle, 2012). Thus in CKD, goal of treatment with vitamin $\mathrm{D}$ and calcitriol is to normalize calcium and phosphate homeostasis, suppress PTH and maintain optimal skeletal health.

c) Vascular calcification: role of vitamin D in vascular complications related to CKD. Vascular calcifications develop early in CKD, and their prevalence increases as GFR declines such that approximately $80 \%$ of incident adult dialysis patients have evidence of coronary artery calcification (Budoff et al., 2011; Qunibi et al., 2005). Calcification of vessels begins in pre dialysis CKD and mean serum phosphorus, calcium and PTH levels and dialysis duration have been associated with calcification scores and carotid intimal medial thickness in both children and adults (Shroff et al., 2008; Schoppet et al., 2008; Shroff et al., 2007). Across the spectrum of CKD, large observational studies in adults have shown that biochemical abnormalities of CKD-MBD, vascular calcification, and bone fragility are associated with increased risks for morbidity and mortality (KDIGO, 2009).

Pathophysiology of vascular calcification in CKD is unique in that the disease process is limited to tunica media of small and medium sized blood vessels compared to atherosclerosis which affects the general population where the disease process involves tunica intima of larger blood vessels. Pathognomonic findings of medial vascular calcification include osteochondrogenic differentiation and apoptosis of vascular smooth muscle cells, instability and release of extracellular vesicles loaded calcium and phosphate, and elastin degradation (Yamada and Giachelli, 2017). Several systemic and local inhibitors and inducers of vascular calcification have been identified in rodent models of CKD including hypercalcemia and hyperphosphatemia. In vitro studies demonstrate that increasing extracellular concentrations of calcium and phosphate in the media activate signaling pathways that promote osteochondrogenic differentiation of vascular smooth muscle cells, induce apoptosis and formation of extracellular matrix vesicles that form the nidus for calcification. In rodent models of CKD, vitamin 
Table 3

Classification of renal osteodystrophy by bone histomorphometry.

\begin{tabular}{|c|c|c|c|c|}
\hline & Characteristic features & Bone turnover & Bone mineralization & Bone volume \\
\hline Osteitis fibrosa & $\begin{array}{l}\text { - } \mathrm{Nl} \text { or } \uparrow \uparrow \text { osteoid volume } \\
\text { - } \uparrow \uparrow \text { osteoclast activity } \\
\text { - } \uparrow \uparrow \text { osteoclast number } \\
\text { - } \uparrow \text { Fibrosis } \\
\text { - } \uparrow \uparrow \text { bone formation rate }\end{array}$ & $\uparrow$ & Normal & $\uparrow, \downarrow$ or normal \\
\hline Mild HPT & $\begin{array}{l}\text { - } \mathrm{Nl} \text { or } \uparrow \text { osteoid volume } \\
\text { - } \uparrow \text { osteoclast activity } \\
\text { - } \uparrow \text { osteoclast number } \\
\text { - } \uparrow \text { bone formation rate }\end{array}$ & Normal or mild $\uparrow$ & Normal & $\uparrow, \downarrow$ or normal \\
\hline Osteomalacia & $\begin{array}{l}\text { - } \uparrow \uparrow \text { osteoid volume } \\
\text { - } \mathrm{Nl} \text { or } \downarrow \text { osteoclast activity } \\
\text { - } \downarrow \text { osteoclast number } \\
\text { - } \downarrow \downarrow \text { bone formation rate }\end{array}$ & $\downarrow$ & Abnormal & $\uparrow, \downarrow$ or normal \\
\hline Adynamic & $\begin{array}{l}\text { - } \mathrm{Nl} \text { or } \downarrow \text { osteoid volume } \\
\text { - } \downarrow \text { osteoclast activity } \\
\text { - } \downarrow \text { osteoclast number } \\
\text { - } \downarrow \downarrow \text { bone formation rate }\end{array}$ & $\downarrow$ & Normal & $\uparrow, \downarrow$ or normal \\
\hline
\end{tabular}

Nl- Normal, $\downarrow$-low, $\uparrow$-high, HPT- hyperparathyroidism.

D receptor agonists (VDRA) decreased aortic calcification (Lau et al., 2012; Mathew et al., 2008) and in vitro studies demonstrate that treatment with calcitriol and paricalcitol directly inhibit calcification induced by cocultures of vascular smooth muscle cells with macrophages (Li et al., 2010). However, in humans with CKD, the role of VDRA therapy to prevent vascular calcifications remains controversial (KDIGO, 2017).

\section{Diagnosis and treatment of CKD-MBD}

\subsection{KDIGO guidelines}

Most recent KDIGO guidelines published in 2017 recommend monitoring serum levels of calcium, phosphate, PTH, and alkaline phosphatase activity beginning in CKD stage G3a $(45-59 \mathrm{ml} / \mathrm{min}$ / $\left.1.73 \mathrm{~m}^{2}\right)$ in adults, and CKD stage G2 $\left(60-89 \mathrm{ml} / \mathrm{min} / 1.73 \mathrm{~m}^{2}\right)$ in children (Levin et al., 2007). However, sufficient clinical data is lacking to provide precise recommendations for target levels of calcium, phosphorus and PTH to maintain optimal bone health and prevent cardiovascular complications. Current recommendation is to evaluate modifiable factors when PTH levels were "above" the upper limit of normal and to initiate treatment when PTH levels are "progressively rising or persistently above the upper normal limit." The KDIGO guideline update provides the following rationale for its emphasis on not initiating treatment for a single elevated PTH value: (1) the optimal PTH concentration remains undefined; (2) a modest increase in PTH concentration is an appropriate adaptive response that contributes to phosphaturia in CKD and may therefore be beneficial for maintenance of normal serum phosphate levels as glomerular filtration rate (GFR) declines; and (3) resistance to skeletal effects of PTH may not necessitate correction of modestly elevated PTH to normal levels in CKD (Levin et al., 2007). The lack of specific evidence-based guidelines poses significant challenges in clinical practice to tailor therapy for CKD-MBD such that cardiovascular and skeletal complications can be minimized while optimizing therapy to maintain skeletal growth and integrity in children.

Current standard of care in CKD-MBD is to use a combined approach aimed at a) reducing serum phosphate concentrations by dietary phosphate restriction and phosphate binder therapy, b) maintaining normal serum calcium and suppressing PTH production by treatment with VDRAs or calcimimetics, and c) vitamin D supplementation to correct vitamin D deficiency. Of note, vitamin D deficiency is common in patients with CKD with $\sim 30-60 \%$ prevalence rate in CKD stages 3-5 (Cali and Russell, 1991). Several studies have shown that administration of VDRAs such as calcitriol, paricalcitol, doxercalciferol, and alfacalcidol are effective in suppression of PTH levels in CKD. However, VDRA therapy in patients with CKD has not been proven to improve patient outcomes by randomized controlled trials. Additionally, superiority of a specific VDRA in its efficacy to suppress PTH concentrations has not been consistently demonstrated.

\section{Future directions}

In patients with CKD, FGF23 excess contributes to the pathogenesis of CKD-MBD and is associated with increased cardiovascular risk and mortality (Faul et al., 2011; Isakova et al., 2011b; Gutierrez et al., 2008). However, optimal FGF23 concentrations required to prevent such complications are yet to be established by clinical trials. Novel therapeutic strategies to reduce serum phosphorus and FGF23 concentrations in patients with CKD are currently under clinical investigation. These include therapies that combine dietary phosphate restriction with inhibitors of intestinal phosphate transport to effectively reduce both active and passive intestinal phosphate absorption. Challenges to treatment strategies that lower FGF23 concentrations in patients who have residual renal function include exacerbation of hyperphosphatemia (by attenuating the phosphaturic effect of FGF23) and potential worsening of hyperparathyroidism. Further studies are needed to establish optimal FGF23 and PTH targets for treatment and prevention of CKD-MBD.

\section{Transparency document}

The Transparency document associated with this article can be found, in online version.

\section{References}

Adams, J.S., Sharma, O.P., Gacad, M.A., Singer, F.R., 1983. Metabolism of 25-hydroxyvitamin $\mathrm{D}_{3}$ by cultured pulmonary alveolar macrophages in sarcoidosis. J. Clin. Invest. 72, 1856-1860.

Al, K.N., Frieling, M., Teh, J.C., Harvey, E., Geary, D.F., 2011. Idiopathic hypercalcemia in infants with renal dysplasia. Clin. Nephrol. 75, 466-471.

Armbrecht, H.J., Okuda, K., Wongsurawat, N., Nemani, R.K., Chen, M.L., Boltz, M.A., 1992. Characterization and regulation of the vitamin D hydroxylases. J. Steroid Biochem. Mol. Biol. 43, 1073-1081.

Bacchetta, J., Harambat, J., Cochat, P., Salusky, I.B., Wesseling-Perry, K., 2012. The consequences of chronic kidney disease on bone metabolism and growth in children. Nephrol. Dial. Transplant. 27, 3063-3071.

Bai, X.Y., Miao, D., Goltzman, D., Karaplis, A.C., 2003. The autosomal dominant hypophosphatemic rickets R176Q mutation in FGF23 resists proteolytic cleavage and enhances in vivo biological potency. J. Biol. Chem. 278, 9843-9849.

Bikle, D.D., 2012. Vitamin D and bone. Curr. Osteoporos. Rep. 10, 151-159.

Bikle, D.D., Nemanic, M.K., Gee, E., Elias, P., 1986. 1,25-Dihydroxyvitamin $D_{3}$ production by human keratinocytes. J. Clin. Invest. 78, 557-566. 
Budoff, M.J., Rader, D.J., Reilly, M.P., Mohler III, E.R., Lash, J., Yang, W., Rosen, L., Glenn, M., Teal, V., Feldman, H.I., 2011. Relationship of estimated GFR and coronary artery calcification in the CRIC (Chronic Renal Insufficiency Cohort) Study. J. Am. Soc. Nephrol. 58, 519-526.

Cali, J.J., Russell, D.W., 1991. Characterization of human sterol 27-hydroxylase. J. Biol. Chem. 266, 7774-7778.

Carpenter, T.O., McPhee, M.D., Bort, R., Mitnick, M.A., Carnes, D.L., 1992. Dissociation of phosphaturia and 25(OH)D-1 $\alpha$-hydroxylase trophism using a novel analogue of parathyroid hormone. Am. J. Phys. 262, E483-E487.

Chan, Y.-L., McKay, C., Dye, E., Slatopolsky, E., 1986. The effect of 1,25-dihydroxycholecalciferol on parathyroid hormone secretion by monolayer cultures of bovine parathyroid cells. Calcif. Tissue Int. 38, 27-32.

Cheng, J.B., Levine, M.A., Bell, N.H., Mangelsdorf, D.J., Russell, D.W., 2004. Genetic evidence that the human CYP2R1 enzyme is a key vitamin D 25-hydroxylase. Proc. Natl. Acad. Sci. U. S. A. 101, 7711-7715.

Coen, G., Messa, F., Massimetti, C., Mazzaferro, S., Manganiello, M., Donato, G., Finistauri, D., Giuliano, G., Cinotti, G.A., 1984. 1-Alpha-oh-cholecalciferol (1-alphaOHD3) and low phosphate diet in predialysis chronic renal failure: effects on renal function and on secondary hyperparathyroidism. Acta Vitaminol. Enzymol. 6, 129-135.

Coen, G., Mazzafero, S., Bonucci, E., Ballanti, P., Massimetti, C., Donato, G., Landi, A., Smacchi, A., Rocca, C.D., Cinotti, G.A., Taggi, F., 1986. Treatment of secondary hyperparathyroidism of predialysis chronic renal failure with low doses of $1,25(\mathrm{OH})$ 2D3: humoral and histomorphometric results. Miner. Electrolyte Metab. 12, 375-382.

Coen, G., Ballanti, P., Bonucci, E., Calabria, S., Costantini, S., Ferrannini, M., Giustini, M., Giordano, R., Nicolai, G., Manni, M., Sardella, D., Taggi, F., 2002. Renal osteodystrophy in predialysis and hemodialysis patients: comparison of histologic patterns and diagnostic predictivity of intact PTH. Nephron 91, 103-111.

David, V., Martin, A., Isakova, T., Spaulding, C., Qi, L., Ramirez, V., ZumbrennenBullough, K.B., Sun, C.C., Lin, H.Y., Babitt, J.L., Wolf, M., 2016. Inflammation and functional iron deficiency regulate fibroblast growth factor 23 production. Kidney Int. 89 (1), 135-146 (January).

Delmez, J.A., Tindira, C., Grooms, P., Dusso, A., Windus, D.W., Slatopolsky, E., 1989. Parathyroid hormone suppression by intravenous 1,25-dihydroxyvitamin D. J. Clin. Invest. 83, 1349-1355.

Denburg, M.R., Tsampalieros, A.K., de Boer, I.H., Shults, J., Kalkwarf, H.J., Zemel, B.S., Foerster, D., Stokes, D., Leonard, M.B., 2013. Mineral metabolism and cortical volumetric bone mineral density in childhood chronic kidney disease. J. Clin. Endocrinol. Metab. 98, 1930-1938.

Denda, M., Finch, J., Brown, A.J., Nishii, Y., Kubodera, N., Slatopolsky, E., 1996. 1,25Dihydroxyvitamin D3 and 22-oxacalcitriol prevent the decrease in vitamin D receptor content in the parathyroid glands of uremic rats. Kidney Int. 50, 34-39.

Di Marco, G.S., Reuter, S., Kentrup, D., Grabner, A., Amaral, A.P., Fobker, M., Stypmann, J., Pavenstadt, H., Wolf, M., Faul, C., Brand, M., 2014. Treatment of established left ventricular hypertrophy with fibroblast growth factor receptor blockade in an animal model of CKD. Nephrol. Dial. Transplant. 29, 2028-2035.

Fang, Y., Ginsberg, C., Sugatani, T., Monier-Faugere, M.C., Malluche, H., Hruska, K.A., 2014. Early chronic kidney disease-mineral bone disorder stimulates vascular calcification. Kidney Int. 85, 142-150.

Faul, C., Amaral, A.P., Oskouei, B., Hu, M.C., Sloan, A., Isakova, T., Gutierrez, O.M., Aguillon-Prada, R., Lincoln, J., Hare, J.M., Mundel, P., Morales, A., Scialla, J., Fischer, M., Soliman, E.Z., Chen, J., Go, A.S., Rosas, S.E., Nessel, L., Townsend, R.R., Feldman, H.I., St John, S.M., Ojo, A., Gadegbeku, C., Di Marco, G.S., Reuter, S., Kentrup, D., Tiemann, K., Brand, M., Hill, J.A., Moe, O.W., Kuro, O., Kusek, J.W., Keane, M.G., Wolf, M., 2011. FGF23 induces left ventricular hypertrophy. J. Clin. Invest. 121, 4393-4408.

Feldman, D., Malloy, P.J., Gross, C., 1996. Vitamin D: metabolism and action. In: Marcus, R., Feldman, D., Kelsey, J. (Eds.), Osteoporosis, 1 ed. Academic Press, San Diego, pp. 205-235.

Fu, G.K., Lin, D., Zhang, M.Y.H., Bikle, D.D., Miller, W.L., Portale, A.A., 1997a. Cloning of human 25-hydroxyvitamin D-1 $\alpha$-hydroxylase and mutations causing vitamin D-dependent rickets type 1. Mol. Endocrinol. 11, 1961-1970.

Fu, G.K., Portale, A.A., Miller, W.L., 1997b. Complete structure of the human gene for the vitamin D 1 $\alpha$-hydroxylase, P450c1 $\alpha$. DNA Cell Biol. 16, 1499-1507.

Goodman, W.G., Ramirez, J.A., Belin, T.R., Chon, Y., Gales, B., Segre, G.V., Salusky, I.B., 1994. Development of adynamic bone in patients with secondary hyperparathyroidism after intermittent calcitriol therapy. Kidney Int. 46, 1160-1166.

Grob, F., Zambrano, P., Ibarra, X., Reyes, M.L., 2013. Parathyroid hormone-independent hypercalcemia in an infant with renal dysplasia: possible role of PTHrP. J. Pediatr. Endocrinol. Metab. 26, 365-367.

Gutierrez, O., Isakova, T., Rhee, E., Shah, A., Holmes, J., Collerone, G., Juppner, H., Wolf, M., 2005. Fibroblast growth factor-23 mitigates hyperphosphatemia but accentuates calcitriol deficiency in chronic kidney disease. J. Am. Soc. Nephrol. 16, 2205-2215.

Gutierrez, O.M., Mannstadt, M., Isakova, T., Rauh-Hain, J.A., Tamez, H., Shah, A., Smith, K., Lee, H., Thadhani, R., Juppner, H., Wolf, M., 2008. Fibroblast growth factor 23 and mortality among patients undergoing hemodialysis. N. Engl. J. Med. 359, 584-592.

Hamdy, N.A., Kanis, J.A., Beneton, M.N., Brown, C.B., Juttmann, J.R., Jordans, J.G., Josse, S., Meyrier, A., Lins, R.L., Fairey, I.T., 1995. Effect of alfacalcidol on natural course of renal bone disease in mild to moderate renal failure. BMJ 310, 358-363.

Hasegawa, H., Nagano, N., Urakawa, I., Yamazaki, Y., Iijima, K., Fujita, T., Yamashita, T., Fukumoto, S., Shimada, T., 2010. Direct evidence for a causative role of FGF23 in the abnormal renal phosphate handling and vitamin D metabolism in rats with earlystage chronic kidney disease. Kidney Int. 78, 975-980.

Henry, H.L., 1979. Regulation of the hydroxylation of 25-hydroxyvitamin $\mathrm{D}_{3}$ in vivo and in primary cultures of chick kidney cells. J. Biol. Chem. 254, 2722-2729.
Howard, G.A., Turner, R.T., Sherrard, D.J., Baylink, D.J., 1981. Human bone cells in culture metabolize 25-hydroxyvitamin $\mathrm{D}_{3}$ to 1 ,25-dihydroxyvitamin $\mathrm{D}_{3}$ and 24,25 dihydroxyvitamin $\mathrm{D}_{3}$. J. Biol. Chem. 256, 7738-7740.

Isakova, T., Wahl, P., Vargas, G.S., Gutierrez, O.M., Scialla, J., Xie, H., Appleby, D., Nessel, L., Bellovich, K., Chen, J., Hamm, L., Gadegbeku, C., Horwitz, E., Townsend, R.R., Anderson, C.A., Lash, J.P., Hsu, C.Y., Leonard, M.B., Wolf, M., 2011a. Fibroblast growth factor 23 is elevated before parathyroid hormone and phosphate in chronic kidney disease. Kidney Int. 79, 1370-1378.

Isakova, T., Xie, H., Yang, W., Xie, D., Anderson, A.H., Scialla, J., Wahl, P., Gutierrez, O.M., Steigerwalt, S., He, J., Schwartz, S., Lo, J., Ojo, A., Sondheimer, J., Hsu, C.Y., Lash, J., Leonard, M., Kusek, J.W., Feldman, H.I., Wolf, M., 2011b. Fibroblast growth factor 23 and risks of mortality and end-stage renal disease in patients with chronic kidney disease. JAMA 305, 2432-2439.

KDIGO, 2009. Clinical practice guideline for the diagnosis, evaluation, prevention, and treatment of Chronic Kidney Disease-Mineral and Bone Disorder (CKD-MBD). Kidney Int. S1-S59.

KDIGO, 2017. Clinical practice guideline update for the diagnosis, evaluation, prevention, and treatment of Chronic Kidney Disease-Mineral and Bone Disorder (CKD-MBD). Kidney Int. S1-S59.

Kodous, N., Filler, G., Sharma, A.P., Van Hooren, T.A., 2015. PTHrP-related hypercalcaemia in infancy and congenital anomalies of the kidney and urinary tract (CAKUT). Can. J. Kidney Health Dis. 2, 21.

Larsson, T., Marsell, R., Schipani, E., Ohlsson, C., Ljunggren, O., Tenenhouse, H.S., Juppner, H., Jonsson, K.B., 2004. Transgenic mice expressing Fibroblast Growth Factor 23 under the control of the $\alpha 1$ (I) collagen promoter exhibit growth retardation, osteomalacia and disturbed phosphate homeostasis. Endocrinology 145, 3087-3094.

Lau, W.L., Leaf, E.M., Hu, M.C., Takeno, M.M., Kuro, O., Moe, O.W., Giachelli, C.M., 2012. Vitamin D receptor agonists increase klotho and osteopontin while decreasing aortic calcification in mice with chronic kidney disease fed a high phosphate diet. Kidney Int. 82 (12), 1261-1270 (2 December).

Levin, A., Bakris, G.L., Molitch, M., Smulders, M., Tian, J., Williams, L.A., Andress, D.L., 2007. Prevalence of abnormal serum vitamin D, PTH, calcium, and phosphorus in patients with chronic kidney disease: results of the study to evaluate early kidney disease. Kidney Int. 71, 31-38.

Li, X., Speer, M.Y., Yang, H., Bergen, J., Giachelli, C.M., 2010. Vitamin D receptor activators induce an anticalcific paracrine program in macrophages: requirement of osteopontin. Arterioscler. Thromb. Vasc. Biol. 30, 321-326.

Mathew, S., Lund, R.J., Chaudhary, L.R., Geurs, T., Hruska, K.A., 2008. Vitamin D receptor activators can protect against vascular calcification. J. Am. Soc. Nephrol. 19, 1509-1519.

Mathias, R., Salusky, I., Harman, W., Paredes, A., Emans, J., Segre, G., Goodman, W., 1993. Renal bone disease in pediatric and young adult patients on hemodialysis in a children's hospital. J. Am. Soc. Nephrol. 3, 1938-1946.

Mazzaferro, S., Coen, G., Ballanti, P., Bondatti, F., Bonucci, E., Pasquali, M., Sardella, D., Tomei, E., Taggi, F., 1990. Osteocalcin, iPTH, alkaline phosphatase and hand x-ray scores as predictive indices of histomorphometric parameters in renal osteodystrophy. Nephron 56, 261-266.

Moe, S., Drueke, T., Cunningham, J., Goodman, W., Martin, K., Olgaard, K., Ott, S., Sprague, S., Lameire, N., Eknoyan, G., 2006. Definition, evaluation, and classification of renal osteodystrophy: a position statement from Kidney Disease: Improving Global Outcomes (KDIGO). Kidney Int. 69, 1945-1953.

Murayama, A., Takeyama, K., Kitanaka, S., Kodera, Y., Kawaguchi, Y., Hosoya, T., Kato, S., 1999. Positive and negative regulations of the renal 25-hydroxyvitamin $D_{3} 1 \alpha$ hydroxylase gene by parathyroid hormone, calcitonin, and $1 \alpha, 25(\mathrm{OH})_{2} \mathrm{D}_{3}$ in intact animals. Endocrinology 140, 2224-2231.

Pereira, R.C., Juppner, H., Azucena-Serrano, C.E., Yadin, O., Salusky, I.B., WesselingPerry, K., 2009. Patterns of FGF-23, DMP1, and MEPE expression in patients with chronic kidney disease. Bone 45, 1161-1168.

Perwad, F., Zhang, M.Y., Tenenhouse, H.S., Portale, A.A., 2007. Fibroblast growth factor 23 impairs phosphorus and vitamin D metabolism in vivo and suppresses 25-hydroxyvitamin D-1alpha-hydroxylase expression in vitro. Am. J. Physiol. Ren. Physiol 293, F1577-F1583.

Portale, A.A., Perwad, F., Miller, W.L., 2011. Rickets due to hereditary abnormalities of vitamin D synthesis or action. In: Pediatric Bone - Biology and Diseases, 2nd ed. Elsevier Science, New York, pp. 679-698.

Portale, A.A., Wolf, M., Juppner, H., Messinger, S., Kumar, J., Wesseling-Perry, K., Schwartz, G.J., Furth, S.L., Warady, B.A., Salusky, I.B., 2014. Disordered FGF23 and mineral metabolism in children with CKD. Clin. J. Am. Soc. Nephrol. 9, 344-353.

Qunibi, W.Y., Abouzahr, F., Mizani, M.R., Nolan, C.R., Arya, R., Hunt, K.J., 2005. Cardiovascular calcification in Hispanic Americans (HA) with chronic kidney disease (CKD) due to type 2 diabetes. Kidney Int. 68, 271-277.

Sabbagh, Y., Graciolli, F.G., O'Brien, S., Tang, W., dos Reis, L.M., Ryan, S., Phillips, L., Boulanger, J., Song, W., Bracken, C., Liu, S., Ledbetter, S., Dechow, P., Canziani, M.E., Carvalho, A.B., Jorgetti, V., Moyses, R.M., Schiavi, S.C., 2012. Repression of osteocyte Wnt/beta-catenin signaling is an early event in the progression of renal osteodystrophy. J. Bone Miner. Res. 27, 1757-1772.

Schoppet, M., Shroff, R.C., Hofbauer, L.C., Shanahan, C.M., 2008. Exploring the biology of vascular calcification in chronic kidney disease: what's circulating? Kidney Int. 73, 384-390.

Shigematsu, T., Kazama, J.J., Yamashita, T., Fukumoto, S., Hosoya, T., Gejyo, F., Fukagawa, M., 2004. Possible involvement of circulating fibroblast growth factor 23 in the development of secondary hyperparathyroidism associated with renal insufficiency. J. Am. Soc. Nephrol. 44, 250-256.

Shimada, T., Mizutani, S., Muto, T., Yoneya, T., Hino, R., Takeda, S., Takeuchi, Y., Fujita, T., Fukumoto, S., Yamashita, T., 2001. Cloning and characterization of FGF23 as a 
causative factor of tumor-induced osteomalacia. Proc. Natl. Acad. Sci. U. S. A. 98, 6500-6505.

Shroff, R.C., Donald, A.E., Hiorns, M.P., Watson, A., Feather, S., Milford, D., Ellins, E.A., Storry, C., Ridout, D., Deanfield, J., Rees, L., 2007. Mineral metabolism and vascular damage in children on dialysis. J. Am. Soc. Nephrol. 18, 2996-3003.

Shroff, R.C., Shah, V., Hiorns, M.P., Schoppet, M., Hofbauer, L.C., Hawa, G., Schurgers, L.J., Singhal, A., Merryweather, I., Brogan, P., Shanahan, C., Deanfield, J., Rees, L., 2008. The circulating calcification inhibitors, fetuin-A and osteoprotegerin, but not matrix Gla protein, are associated with vascular stiffness and calcification in children on dialysis. Nephrol. Dial. Transplant. 23, 3263-3271.

Sugimoto, T., Ritter, C., Slatopolsky, E., Morrissey, J., 1988. Effect of 1,25-dihydroxyvitamin $\mathrm{D}_{3}$ on phospholipid metabolism in cultured bovine parathyroid cells.
Endocrinology 122, 2387-2392.

Tanaka, Y., DeLuca, H.F., 1984. Rat renal 25-hydroxyvitamin $\mathrm{D}_{3} 1$ - and 24-hydroxylases: their in vivo regulation. Am. J. Phys. 246, E168-E173.

Wesseling-Perry, K., Pereira, R.C., Tseng, C.H., Elashoff, R., Zaritsky, J.J., Yadin, O., Sahney, S., Gales, B., Juppner, H., Salusky, I.B., 2012. Early skeletal and biochemical alterations in pediatric chronic kidney disease. Clin. J. Am. Soc. Nephrol. 7, 146-152. Widdowson, E.M., Dickerson, J.W.T., 1964. Chemical composition of the body. In: Comar, C.L., Bronner, F. (Eds.), Mineral Metabolism: An Advanced Treatise. 1. Academic Press, New York, pp. 1-247.

Yamada, S., Giachelli, C.M., 2017. Vascular calcification in CKD-MBD: roles for phosphate, FGF23, and Klotho. Bone 100, 87-93. 